\title{
Small and Robust All-Polymer Fiber Bragg Grating based pH Sensor
}

\author{
Janting, Jakob; Pedersen, Jens; Woyessa, Getinet; Nielsen, Kristian; Bang, Ole
}

Published in:

Journal of Lightwave Technology

Link to article, DOI:

10.1109/JLT.2019.2902638

Publication date:

2019

Document Version

Peer reviewed version

Link back to DTU Orbit

Citation (APA):

Janting, J., Pedersen, J., Woyessa, G., Nielsen, K., \& Bang, O. (2019). Small and Robust All-Polymer Fiber Bragg Grating based pH Sensor. Journal of Lightwave Technology, 37(18), 4480 - 4486.

https://doi.org/10.1109/JLT.2019.2902638

\section{General rights}

Copyright and moral rights for the publications made accessible in the public portal are retained by the authors and/or other copyright owners and it is a condition of accessing publications that users recognise and abide by the legal requirements associated with these rights.

- Users may download and print one copy of any publication from the public portal for the purpose of private study or research.

- You may not further distribute the material or use it for any profit-making activity or commercial gain

- You may freely distribute the URL identifying the publication in the public portal

If you believe that this document breaches copyright please contact us providing details, and we will remove access to the work immediately and investigate your claim. 


\title{
Small and Robust All-polymer Fiber Bragg Grating based $\mathrm{pH}$ Sensor
}

\author{
Jakob Janting, Member, OSA, Jens K. M. Pedersen, Getinet Woyessa, Kristian Nielsen, \\ and Ole Bang, Life Fellow, OSA
}

\begin{abstract}
The smallest all-polymer optical fiber Bragg grating based transducer element for $\mathrm{pH}$ sensing is presented. We show that, considering it's size and robustness, it out-performs similar state-of-the-art fiber Bragg grating based $\mathrm{pH}$ sensors regarding both sensitivity and response time.

A $5 \mu \mathrm{m}-10 \mu \mathrm{m}$ thick $\mathrm{pH}$ sensitive hydrogel coating is placed on a PMMA based microstructured Polymer Optical Fiber Bragg Grating (mPOFBG). The hydrogel expands or contracts depending on the $\mathrm{pH}$ and thus changes in $\mathrm{pH}$ are monitored by following the fiber strain induced changes in the reflected Bragg wavelength $\lambda_{B}$. Prior to applying the hydrogel coating the $\mathrm{mPOF}$ is etched from $150 \mu \mathrm{m}$ to $80 \mu \mathrm{m}$ to enhance sensitivity and surface crazing is introduced with a 50/50 vol\% solution of acetone and methanol to enhance spreading of the hydrogel during the application and adhesion after cure. With this design we achieved a sensitivity of $\Delta \lambda_{B}=73 \mathrm{pm} / \mathrm{pH} \pm 2 \mathrm{pm} / \mathrm{pH}$ and response times below 4.5 mins. for pH 5 - 7 and $4-7$ respectively and a thermal cross sensitivity of $31.4 \mathrm{pm} /{ }^{\circ} \mathrm{C} \pm 0.4 \mathrm{pm} /{ }^{\circ} \mathrm{C}$.
\end{abstract}

Index Terms-Fiber optics, Fiber Bragg gratings, Etching, Optical sensors, Chemical sensors, Optical polymers, Polymer gels, pH measurement.

\section{INTRODUCTION}

$\mathbf{T}$ HE need for real time detection of various chemical parameters such as $\mathrm{pH}$, glucose, blood gases, proteins, antibiotics, toxins and many others is of growing interest. Typically, measurement of these parameters relies on a sample to be taken, followed by a time consuming analysis using tabletop instruments. Especially, in critical care, continuously being able to monitor these parameters would be desirable. Probably the most investigated of these parameters is $\mathrm{pH}$, as it is important for a long range of chemical processes, not only in the biomedical field, but generally also in biology, environmental control and industry.

Various fiber optic $\mathrm{pH}$ sensors have previously been developed. The first fiber optic based $\mathrm{pH}$ sensor to be demonstrated was based on two plastic optical fibers with a light scattering sensing element at the end [1]. This sensing element consisted of scattering particles and an indicator dye with an absorbance spectrum depending of the $\mathrm{pH}$ value of the environment. By measuring the intensity of the absorbance peak of the scattered

Manuscript received....

J. Janting, G. Woyessa and O. Bang are with DTU Fotonik, Department of Photonics Engineering, Technical University of Denmark, 2800 Kongens Lyngby, Denmark (e-mails: jajant@fotonik.dtu.dk, gewoy@fotonik.dtu.dk, oban@fotonik.dtu.dk)

J. K. M. Pedersen is with OFS Fitel Denmark ApS, Priorparken 680, 2605 Brøndbyvester, Denmark (e-mail: jmp@jmpconsult.dk)

K. Nielsen and O. Bang are with SHUTE Sensing Solutions A/S, Oldenvej 1A, 3490 Kvistgård, Denmark (e-mails: kn@shute.dk, oban@fotonik.dtu.dk) light picked up by the return fiber, the $\mathrm{pH}$ value could be extracted and was demonstrated by in-vivo measurements of the $\mathrm{pH}$ value of sheep blood. Since then, multiple fiber optic $\mathrm{pH}$ sensors have been demonstrated [2]-[5]. Many of the reported techniques rely on either intensity based or spectral reflection measurements of the absorbance spectrum of an indicator dye [2], [4], interferometric measurements of the $\mathrm{pH}$ induced change in thickness / refractive index of a thin coating placed at the end of the fiber or different types of fiber optic refractometers [3].

Polymer Optical Fiber Bragg Gratings (POFBGs) have several properties making them interesting for biomedical applications. Their small size, biocompatibility, reflection mode interrogation and spectral multiplexing capability are all favorable characteristics making a great potential for e.g. in-vivo sensing. However, FBGs inscribed in POFs are not themselves intrinsically sensitive towards the biochemical elements of interest. In order to make POFBGs a viable technology within chemical sensing and biosensing they need to be chemically activated in terms of a transduction scheme capable of transforming the measurand into a signal that can be picked up by one of the intrinsic sensing mechanisms of the FBG. Hydrogel polymers placed on the FBG is one solution.

Hydrogels are crosslinked polymers with a very hydrophilic structure making them able to absorb and retain very large amounts of water without dissolving. They offer a high degree of biocompatibility and are extensively used within the biomedical field, e.g., as wound-healing agents, in contact lenses, as drug delivery systems, bioadhesives and within bioand chemical sensing [6]. They also offer a high degree of flexibility in the sense that they can be chemically engineered to possess various mechanical properties and biochemical responsiveness. Synthesis of various types of hydrogels responsive towards different external stimuli such as changes in $\mathrm{pH}$ [7], [8], solvent composition [9], electrical field values [10] and ionic strength [11] have been demonstrated. Moreover, the ability of using hydrogels as molecular recognition elements for e.g. antigens and specific DNA have been reported [12][15]. The typical response of these hydrogels is that they in an aqueous solution undergo a phase transition and consequently dramatic volumetric change as the measurand value changes. The swelling/shrinking mechanism is based on balanced osmotic pressures inside the gel [11]. At equilibrium the total osmotic pressure change $\Delta \phi$ inside the gel is:

$$
\Delta \phi=\Delta \phi_{\text {elast }}+\Delta \phi_{\text {mix }}+\Delta \phi_{\text {ion }}+\Delta \phi_{\text {bath }}=0
$$

where $\Delta \phi_{\text {mix }}, \Delta \phi_{i o n}$ are the osmotic pressure changes from 
mixing of the gel with water and from electrostatic repulsion of ionized groups in the gel, respectively. Both of these contributions will expand the gel and be counteracted by $\Delta \phi_{\text {elast }}$, the pressure exerted by the gel due to its elasticity and $\Delta \phi_{\text {bath }}$ the pressure due to the solutions ionic strength. The $\mathrm{pH}$ responsive hydrogels contain either acidic or basic groups that can be ionized by changes in the solution $\mathrm{pH}$. For instance, in basic surroundings the acidic groups will deprotonize according to:

$$
[\mathrm{RCOOH}]_{\mathrm{gel}}+\left[\mathrm{OH}^{-}\right]_{\mathrm{aq}} \rightarrow\left[\mathrm{RCOO}^{-}\right]_{\mathrm{gel}}+\mathrm{H}_{2} \mathrm{O}
$$

This increases the charge density inside the gel, increasing the electrostatic repulsion, which induces the phase transition and swelling of the gel. In acidic surroundings, the reverse process happens,

$$
\left[\mathrm{RCOO}^{-}\right]_{\mathrm{gel}}+\left[\mathrm{H}^{+}\right]_{\mathrm{aq}} \rightarrow[\mathrm{RCOOH}]_{\mathrm{gel}}
$$

resulting in reduced electrostatic repulsion and shrinking of the gel [11].

Thus, a hydrogel can work as a mechanical transducer, transferring / releasing strain to the POFBG as the $\mathrm{pH}$ changes, which is detected by corresponding shifts in Bragg reflection wavelength $\lambda_{B}=2 n_{e f f} \Lambda$, where $n_{e f f}$ is the effective refractive index of the fiber and $\Lambda$ is the periodicity of the grating, Fig. 1. The shift in $\lambda_{B}$ due to the applied axial force

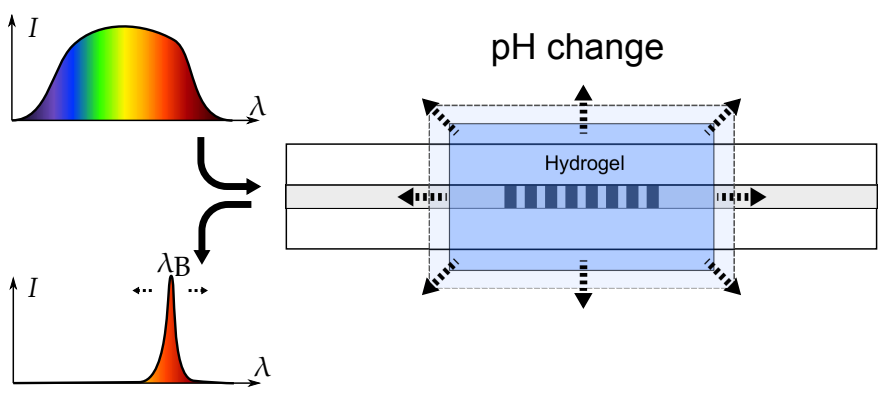

Fig. 1. Illustration of $\mathrm{pH}$ responsive hydrogel coating tranducing scheme.

$F$ from the gel is:

$$
\Delta \lambda_{B}=\lambda_{B}\left(1-P_{\varepsilon}\right) \frac{F}{E A}=\frac{S_{\varepsilon}}{E A} F
$$

where $S_{\varepsilon}=\lambda_{B}\left(1-P_{\varepsilon}\right)$ is the strain sensitivity of the FBG [16], $P_{\varepsilon}$ is the strain-optic or photoelastic coefficient, $E$ is Young's modulus of the fiber and $A$ is the fiber cross sectional area. From this we see, that the sensitivity of the sensor can be increased optically by using a higher $\lambda_{B}$, geometrically by reducing the fiber cross sectional area and mechanically by using a fiber material with lower Young's modulus [17], [18]. Generally, increasing the gel thickness relative to that of the fiber also leads to higher sensitivity and longer response time.

Responsive hydrogels have previously been applied mainly on silica based FBGs. Liu et al. [19] and Cong et al. [20] demonstrated a hydrogel coated FBG sensor based on unetched and etched silica FBGs for measuring salinity. In order to achieve higher sensitivity, the fiber was etched to a final diameter of $40 \mu \mathrm{m}$ and disks were glued to the fiber to act like walls for the hydrogel to push on. Yulianti et al. [21] used a hydrogel based on a composition of hydroxyethylmethacrylate (HEMA) and acrylic acid and showed a response in the $\mathrm{pH}$ 4-7 range with a sensitivity of $114 \mathrm{pm} / \mathrm{pH}$, response times between 9-14 mins. between steps of $1 \mathrm{pH}$ value and a thermal cross sensitivity of $25 \mathrm{pm} /{ }^{\circ} \mathrm{C}$. In order to achieve these results, this silica FBG was also etched to a final diameter of $40 \mu \mathrm{m}$. Etching silica fibers to such a small size generally render it difficult to handle the fiber. Recently, Cheng et al. [22] published the first study where a $\mathrm{pH}$ sensitive gel, poly(ethylene glycol) diacrylate (PEGDA), was applied to a PMMA based POFBG. They achieved a $\mathrm{pH}$ sensitivity of up to $-0.41 \mathrm{~nm} / \mathrm{pH}$ (fiber etched from $125 \mu \mathrm{m}$ diameter to 92 $\mu \mathrm{m}$ ), a response time of $30 \mathrm{~s}$ (fiber original diameter $125 \mu \mathrm{m}$ ), and a thermal cross-sensitivity of $10 \mathrm{pm} /{ }^{\circ} \mathrm{C}$ (fiber diameter $125 \mu \mathrm{m})$. However, the hydrogel layer around the fiber was square shaped, which means that diffusion length of ions inout will vary, and very thick, in the mm range. Further, the gel was molded around the fiber using the space between two microscope slides as mold and the sensor appears not to have been released from the mold before characterization. These special properties strongly influence the sensors performance and make it difficult to compare with our work and the first mentioned on glass fibers [19]-[21]. For instance, by etching the fiber from $125 \mu \mathrm{m}$ diameter to $92 \mu \mathrm{m}$ they decreased the fiber cross sectional area with $84 \%$ and the sensitivity not equally much as expected from eq. (4), but only $20 \%$, probably due to the influence of the mold confinement of the gel. Also, it should be noted that in all these three examples $\lambda_{B} \approx 1550 \mathrm{~nm}$ have been used, which in itself approximately doubles sensitivity, eq. (4), compared to the more frequently used $\lambda_{B} \approx 850 \mathrm{~nm}$ for POFBGs.

Our work demonstrates, that by using POFBGs, higher sensitivities and faster response times due to the $\sim 25$ times lower Young's modulus of these polymers compared with silica glass, can be reached keeping the sensor all-polymer and small, while retaining a moderate level of thermal crosssensitivity. Moreover, we demonstrate that due to the organic chemical nature of polymers, the surface is easier to manipulate which facilitates processing and leads to better hydrogel adhesion properties and consequently reliability.

\section{EXPERIMENTS AND RESULTS}

\section{A. Fabrication}

The POF used in this work was a PMMA based 2-ring microstructured POF (mPOF) fabricated in-house using the drill-and-draw method, see the cross sectional view in Fig. 2. It has an average diameter of $150 \mu \mathrm{m} \pm 2 \mu \mathrm{m}$ with hole diameters of $2 \mu \mathrm{m}$ and a hole-to-pitch ratio of 0.40 making it endlessly single mode [23]. Prior to FBG inscription, the fiber was annealed in distilled water at $65^{\circ} \mathrm{C}$ for 72 hours to ensure stable sensor performance [24], [25].

Each FBG with $\lambda_{B}=847 \mathrm{~nm}$ was inscribed in less than 7 minutes using the phase mask technique [17], [27], [28], see the setup in Fig. 3. A $325 \mathrm{~nm} \mathrm{CW} \mathrm{HeCd} \mathrm{UV-laser} \mathrm{(IK5751I-}$ $\mathrm{G}$, Kimmon) with the output power attenuated to $18 \mathrm{~mW}$ was focused using a cylindrical lens through a phase mask with a grating pitch of $572.4 \mathrm{~nm}$ (Ibsen Photonics A/S) on the optical 


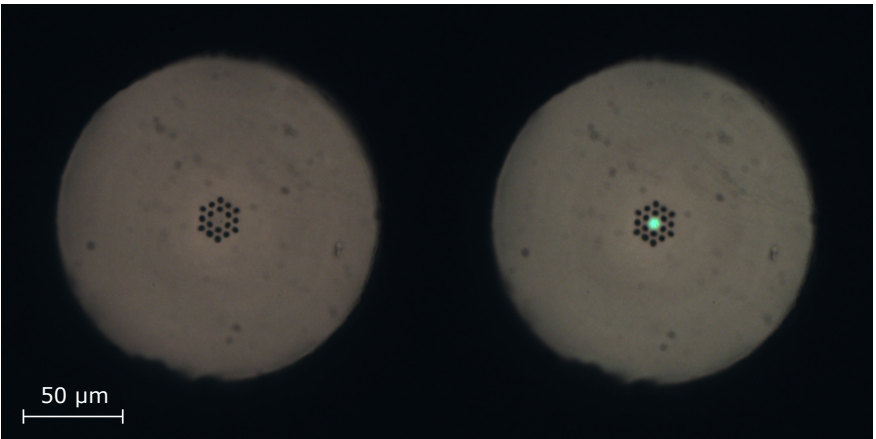

Fig. 2. Fiber profile of a PMMA mPOF with a 2-ring cladding structure. The fiber was cut at $77.5^{\circ} \mathrm{C}$ using the method described by Stefani et al. [26]. Right: Light from an LED coupled into the fiber, showing how the light is confined to the core region.

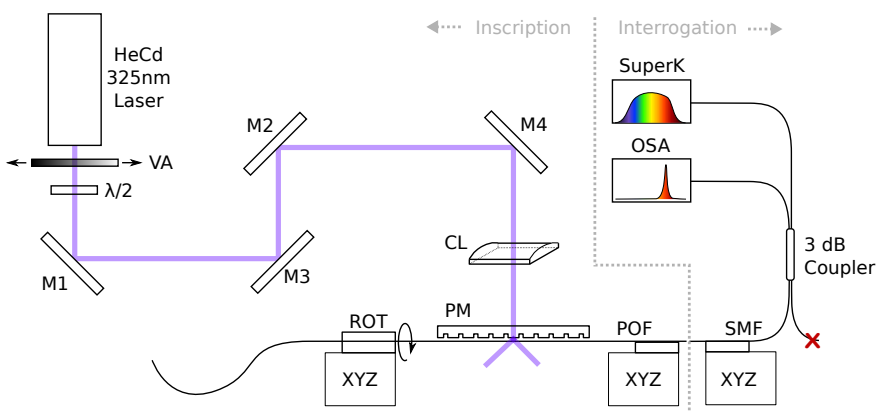

Fig. 3. POFBG inscription setup. VA: Variable attenuator. CL: Cylindrical lens. PM: Phase mask. ROT: Rotatable fiber clamp. POF: Polymer optical fiber under inscription. SMF: Silica single mode fiber pigtail.

fiber while monitoring the peak growth using a reflection mode interrogation setup. The interrogation setup consisted of a supercontinuum laser (SuperK Versa, NKT Photonics A/S) launched into one of the arms of a $3 \mathrm{~dB}$ coupler (TW850R5A2, Thorlabs). One output arm was butt-coupled to the POFBG and the second arm terminated. The reflected light was then led back through the fiber coupler and into a CCD-spectrometer (CCS175M, Thorlabs) connected to a PC. A dynamic gate algorithm [29] was applied on the acquired spectra to achieve a sub-pixel resolution of $\sim 10 \mathrm{pm}$ of the determined Braggwavelength.

After inscription, the end of the mPOFBG was sealed using a UV-curable glue (NOA 68) and etched for 8 mins. in pure acetone (99.9 \%), Fig. 4(1) and Fig. 4(2). The etched section including the FBG was approximately $8 \mathrm{~cm}$ and the final diameter of the fiber was measured to be $80 \mu \mathrm{m} \pm 2 \mu \mathrm{m}$.

The etched section was subsequently submerged in a 50/50 vol\% solution of acetone and methanol for $30 \mathrm{~s}$ which introduced a rough, crazed surface on the fiber, Fig. 4(3). The changed surface morphology resulted in a highly improved wettability and hydrogel adhesion.

The hydrogel was synthesized from the following chemicals from Sigma Aldrich: 2-hydroxyethylmethacrylate, HEMA ( $\geq$ $99 \%, \leq 50 \mathrm{ppm}$ inhibitor), ethylene glycol dimethacrylate, EGDMA (98\%, 90 ppm - 110 ppm inhibitor), methacrylic acid MAA (99 \%, 250 ppm inhibitor) and 2,2-dimethoxy-2phenylacetophenone, DMPA (99\%). Poly-HEMA constitutes

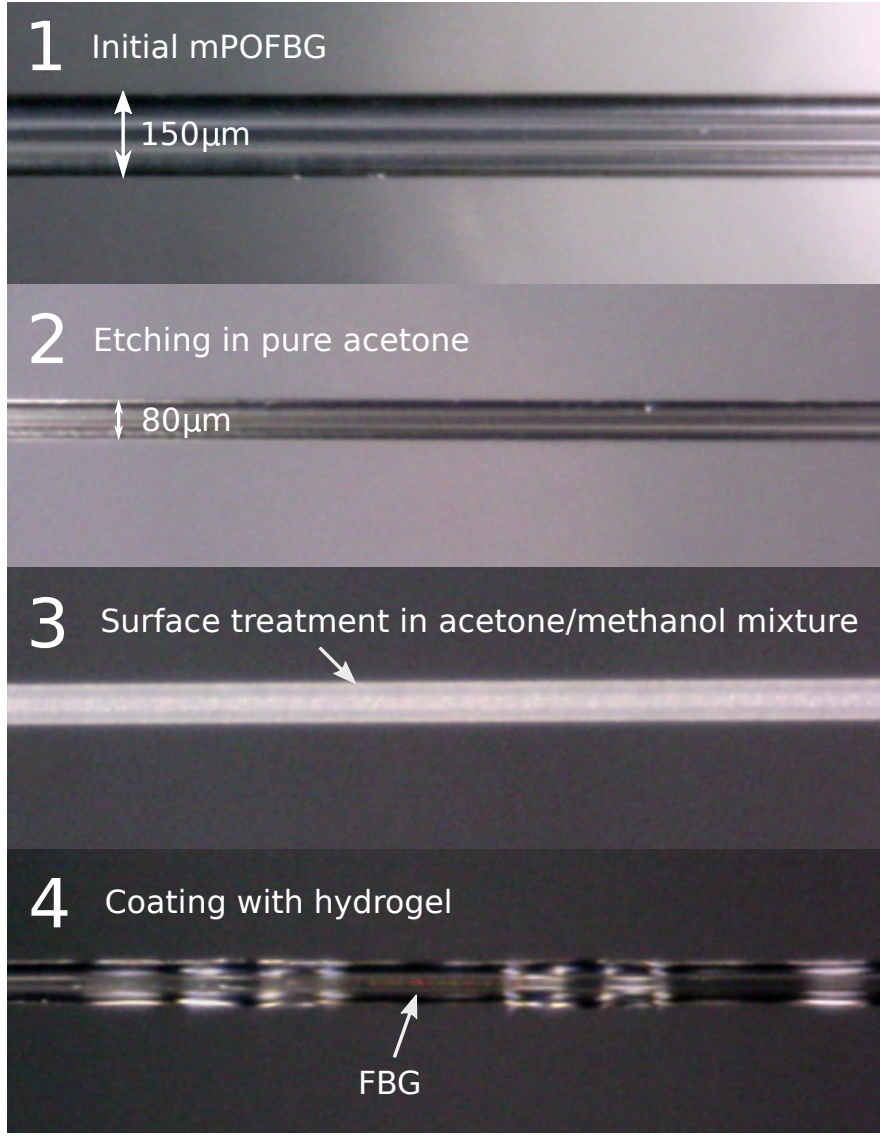

Fig. 4. Four of the different steps involved in the fabrication of the etched mPOFBG hydrogel coated $\mathrm{pH}$ sensor.

the backbone of the polymer, EGDMA is a crosslinker between the HEMA chains, MAA is the component making the polymer $\mathrm{pH}$ sensitive (swelling from $\Delta \phi_{i o n}$, eq. (1)) and DMPA is the photoinitiator with the help of which free radical polymerization comprising all constituents is started, see Fig. 5. The sensor performance depends on which type of hydrogel is used and the relative amount of the reactants. We were inspired by the work of Yetisen et al. [32] to use this hydrogel. They used this $\mathrm{pH}$ responsive hydrogel with an embedded grating-like structure consisting of ordered silver nanoparticles to produce a spectrally encoded signal in white light reflected from the structure. The sensor relied on the displacement of nanoparticles (and thus a change in the grating periodicity) as the hydrogel would shrink or swell based on the $\mathrm{pH}$ of the solution. Their hydrogel was made by mixing equal volumes of a mixture of HEMA, MAA, EGDMA and the photoinitiator DMPA dissolved in isopropanol (IPA). After cure the IPA is evaporated. This leads to a very open and hence soft hydrogel structure, which we found could not induce sufficient strain to the POFBG. Therefore we decided to dissolve DMPA directly in mixtures of HEMA, MAA and EGDMA. Further, a small study was made on varying the relative amounts (wt\%) of the reactants to find a good performing mixture, see Table I. Naturally, the sensitivity of the sensor increases with the amount of MAA because this leads to an increase of $\Delta \phi_{i o n}$ and consequently gel expansion. 
1<smiles>COC(=O)C(OC)(OC)c1ccccc1</smiles><smiles>O=Cc1ccccc1</smiles><smiles>COC(OC)c1ccccc1</smiles>

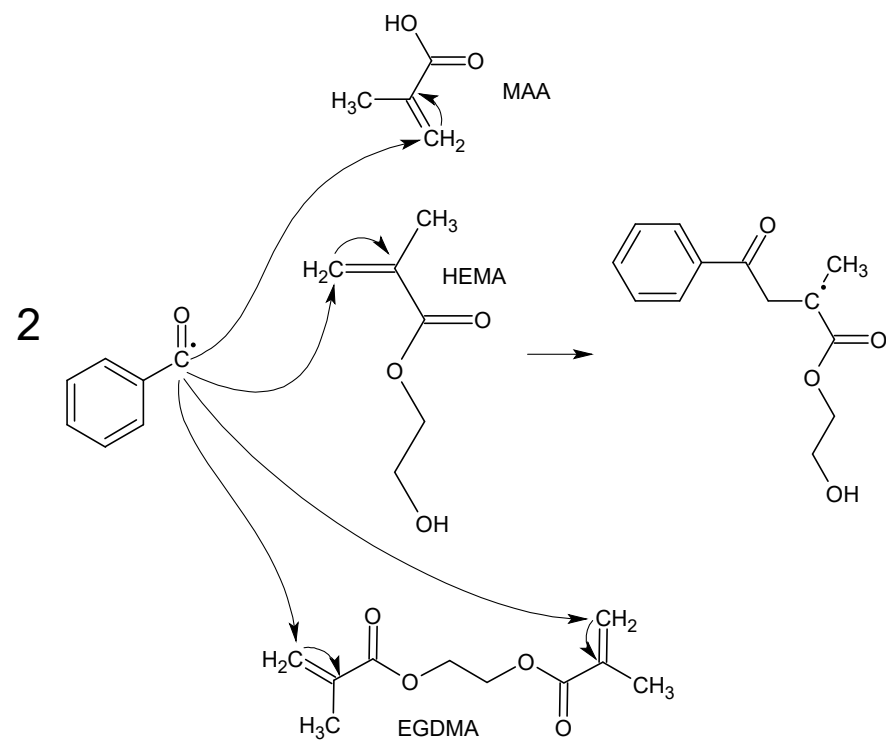

Fig. 5. Hydrogel free radical cure mechanism. Initiation step (1): DMPA is cleaved by the $365 \mathrm{~nm}$ UV irradiation into the two indicated free radicals, [30], [31], of which the benzoyl radical is the most reactive. Propagation step (2): This free radical can then attach HEMA, MAA and EGDMA. The first step of the propagation/polymerization step is only shown in full for the benzoyl reaction with HEMA.

TABLE I

HYDROGEL RECIPES.

\begin{tabular}{|c|c|c|c|c|}
\hline Mixture & HEMA & MAA & EGDMA & DMPA \\
\hline$\# 1$ & $4.5608 \mathrm{~g}(91 \mathrm{wt} \%)$ & $0.2530 \mathrm{~g}(5 \mathrm{wt} \%)$ & $0.1622 \mathrm{~g}(3 \mathrm{wt} \%)$ & $0.0545 \mathrm{~g}(1 \mathrm{wt} \%)$ \\
\hline$\# 2$ & $4.2576 \mathrm{~g}(85 \mathrm{wt} \%)$ & $0.5527 \mathrm{~g}(11 \mathrm{wt} \%)$ & $0.1579 \mathrm{~g}(3 \mathrm{wt} \%)$ & $0.0527 \mathrm{~g}(1 \mathrm{wt} \%)$ \\
\hline \#3 & $3.7995 \mathrm{~g} \mathrm{(76} \mathrm{wt \% )}$ & $1.0009 \mathrm{~g} \mathrm{(20wt} \%)$ & $0.1577 \mathrm{~g}(3 \mathrm{wt} \%)$ & $0.0531 \mathrm{~g}(1 \mathrm{wt} \%)$ \\
\hline \#4 & $2.3057 \mathrm{~g} \mathrm{(46} \mathrm{wt \% )}$ & $2.5059 \mathrm{~g} \mathrm{(50} \mathrm{wt \% )}$ & $0.1588 \mathrm{~g}(3 \mathrm{wt} \%)$ & $0.0519 \mathrm{~g}(1 \mathrm{wt} \%)$ \\
\hline
\end{tabular}

However, to apply a uniform layer to the fiber we found mixture \#3 best and it was therefore used throughout this study.

A broadband laser source was coupled into the fiber making it possible to precisely locate the FBG, as diffracted light from this point can be clearly seen. A drop of the prepared mixture was deposited on a small spatula and brought in contact with the fiber surface close to the FBG under an optical microscope. By slowly moving the drop along the fiber length, it was possible to deposit a very thin film of the hydrogel across the fiber surface, covering the entire FBG, Fig. 4(4). The applied film was cured for 2 mins. using a 365 $\mathrm{nm}$ UV-LED light source (Dymax Bluewave QX4, Ø3 mm lens) at a distance of approximately $1 \mathrm{~cm}$ corresponding to an irradiation energy of $615 \mathrm{~J} / \mathrm{cm}^{2}$. In order to build up the coating layer by layer, $1 \mathrm{~mL}$ of the hydrogel was pre-cured in a $10 \mathrm{~mL}$ beaker by UV-illumination for $15 \mathrm{~s}$ at a distance of approx. $2 \mathrm{~cm}$ corresponding to an irradiation energy of 22 $\mathrm{J} / \mathrm{cm}^{2}$, resulting in a more viscous fluid, which was found to be easier to apply. This pre-cure was not possible to control well enough with mixture \#4 in Table I, where the viscosity became inhomogeneous. The subsequent layers were applied by depositing a drop of the pre-cured hydrogel on the spatula and slowly dragging it along the fiber immediately followed by exposure of the UV-LED for 2 mins. at the $1 \mathrm{~cm}$ distance. This process was repeated five times in total, resulting in a coating of $2.7 \mathrm{~mm}$ length and estimated thickness between $5 \mu \mathrm{m}$ and $10 \mu \mathrm{m}$. Without the previously mentioned surface roughening, see Fig. 4(3), and this application procedure it was impossible to get a nice uniform reliable hydrogel coating on the POFBG. Hydrogel application without these steps included lead to big asymmetric drops, which easily fell off the fiber and in attempts to mechanically spread the uncured material along the fiber using a spatula as described above, the coating tends to quickly break up into smaller drops like in Fig. 6 .

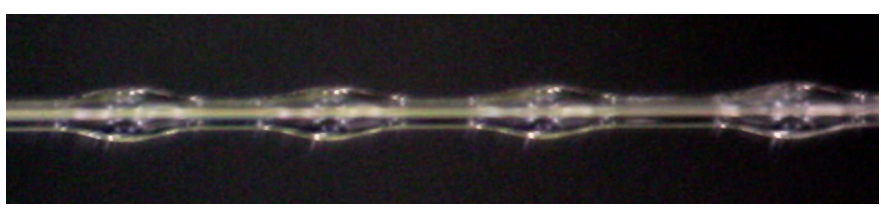

Fig. 6. Droplets forming along the fiber due to poor wettability as the hydrogel monomer mixture is applied.

After applying the coating and before characterization, the sensor was annealed in demineralized water at $60^{\circ} \mathrm{C}$ overnight in order to drive out solvent residuals from the etching process and was placed in $\mathrm{pH} 7$ buffer at room temperature for 24 hours. A drawing of the final sensor corresponding to Fig. 4(4) is shown in Fig. 7.

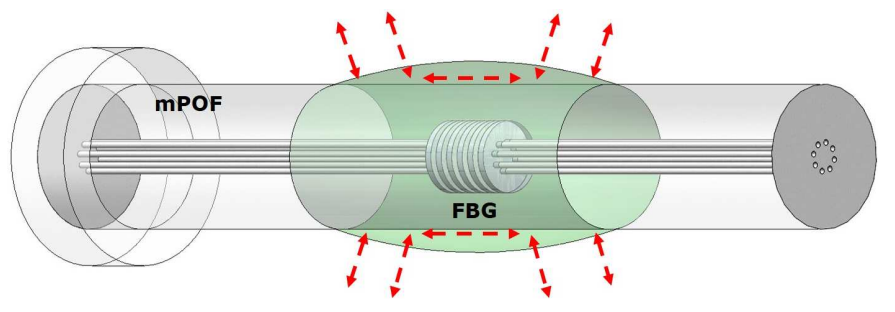

Fig. 7. Sensor concept where a FBG is first inscribed in a mPOF which is then etched down close to the cladding consisting of rings of holes along the fiber and finally a hydrogel (green), which responds to surrounding stimuli by expansion or contraction (red arrows), is placed on the fiber at the FBG location. For clarity only one of the two rings of holes in the mPOF is shown.

\section{B. Characterization}

The sensor response times were found using $\mathrm{pH} 4$ and 7 buffers. The sensor was conditioned by cycling between the two buffers multiple times. The Bragg wavelength was sampled and recorded continuously with a 1-second interval. The sensor was immersed in $\mathrm{pH} 4$ buffer solution and allowed to stabilize for several hours before switching to $\mathrm{pH}$ 7. Three cycles of switching between $\mathrm{pH} 4$ and 7 were carried out, see 
Fig 8 . The response times $\mathrm{T}_{90 \%}$ corresponding to $90 \%$ of the full Bragg-wavelength shift are summarized in Table II. To

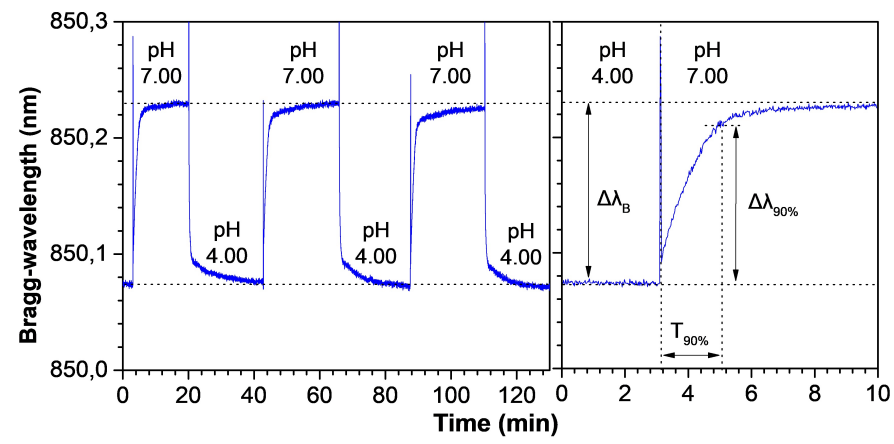

Fig. 8. Repeated cycles between $\mathrm{pH} 4$ and $\mathrm{pH}$ 7. Right: Close-up of the $\mathrm{pH}$ sensor response of the first cycle.

TABLE II

MEASURED RESPONSE TIMES $\mathrm{T}_{90 \%}$ AND BRAGG-WAVELENGTH SHIFTS FOR THE THREE CYCLES SHOWN IN FIG. 8 FOR THE CHANGE BETWEEN PH 4 AND $\mathrm{PH} 7$.

\begin{tabular}{c|ccc}
\hline \hline & Cycle 1 & Cycle 2 & Cycle 3 \\
\hline pH $4 \rightarrow 7$ & 1.9 mins. & 3.4 mins. & 2 mins. \\
pH $7 \rightarrow 4$ & 3.0 mins. & 4.5 mins. & 3.5 mins. \\
\hline$\Delta \lambda_{B}$ & $153 \mathrm{pm} \pm 6 \mathrm{pm}$ & $156 \mathrm{~nm} \pm 6 \mathrm{pm}$ & $154 \mathrm{pm} \pm 6 \mathrm{pm}$ \\
\hline
\end{tabular}

obtain a value for $\lambda_{B}$ at each $\mathrm{pH}$-level, the last 60 samples before a $\mathrm{pH}$ change were used to calculate the mean and standard deviation. The standard deviation was below $2 \mathrm{pm}$ for all values. The values obtained for $\lambda_{B}$ at each $\mathrm{pH}$ level are plotted in Fig. 9.

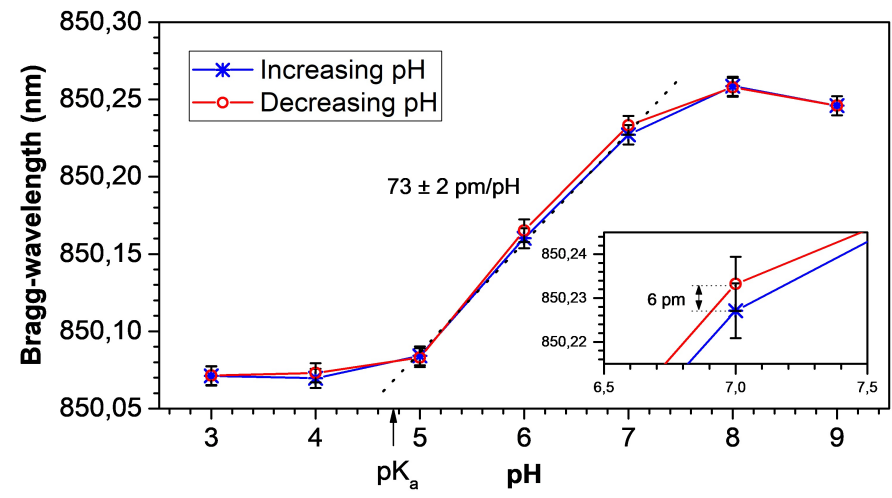

Fig. 9. Calibration curve of the $80 \mu \mathrm{m}$ diameter etched mPOFBG hydrogel coated $\mathrm{pH}$ sensor. Inset: Maximum hysteresis found at $\mathrm{pH} 7$.

The uncertainty in the Bragg-wavelength due to thermal fluctuations for a mPOFBG without hydrogel was on the order of $6 \mathrm{pm}$, corresponding to the maximum observed deviation in temperature $0.2{ }^{\circ} \mathrm{C}$ of the buffer solutions throughout the experiments and thus the dominant uncertainty related to the determination of $\lambda_{B}$, which is indicated by error bars in the figure. The maximum hysteresis was measured to be $6 \mathrm{pm}$ at $\mathrm{pH} \mathrm{7,} \mathrm{which} \mathrm{is} \mathrm{similar} \mathrm{to} \mathrm{the} \mathrm{estimated} \mathrm{uncertainty} \mathrm{due} \mathrm{to}$ thermal fluctuations.
The sensor exhibits the largest response and linearity in the $\mathrm{pH}$ 5-7 range. The estimated sensitivity (found by a linear fit of the six data points in this range, Fig. 9) is $73 \mathrm{pm} / \mathrm{pH} \pm$ $2 \mathrm{pm} / \mathrm{pH}$, indicating that $\mathrm{pH}$ changes of 0.08 in the range of $\mathrm{pH}$ 5-7 can be resolved using this sensor (given a measurement uncertainty of $6 \mathrm{pm}$ ). The sensitivity found for this sensor is comparable with the hydrogel coated $40 \mu \mathrm{m}$ thick silica FBG presented by Yulianti et al. [21]. However, it should be noted that the 4 times larger fiber cross section area and half the operation wavelength of the mPOFBG sensor means that the final sensitivity in principle is downscaled relative to the silicabased sensor with a factor of 8, c.f. equation (4). Moreover, the response times presented here are less than half.

A decrease in $\lambda_{B}$ going from $\mathrm{pH} 8$ to 9 is observed as shown in Figs. 9 and 10. This is due to an intrinsic dependency on the ionic strength of the solution. MAA has a $\mathrm{pKa}$ value of 4.66. As the $\mathrm{pH}$ approaches 9, the carboxyl groups are fully dissociated and thus additional increase in $\mathrm{pH}$ does not lead to further swelling. However, the increased $\mathrm{pH}$ is related to an increase in ionic strength, causing de-swelling of the hydrogel [8], [11]. The ionic strengths of the buffer solutions used here are not known and further investigations to determine the magnitude of this cross sensitivity are needed.

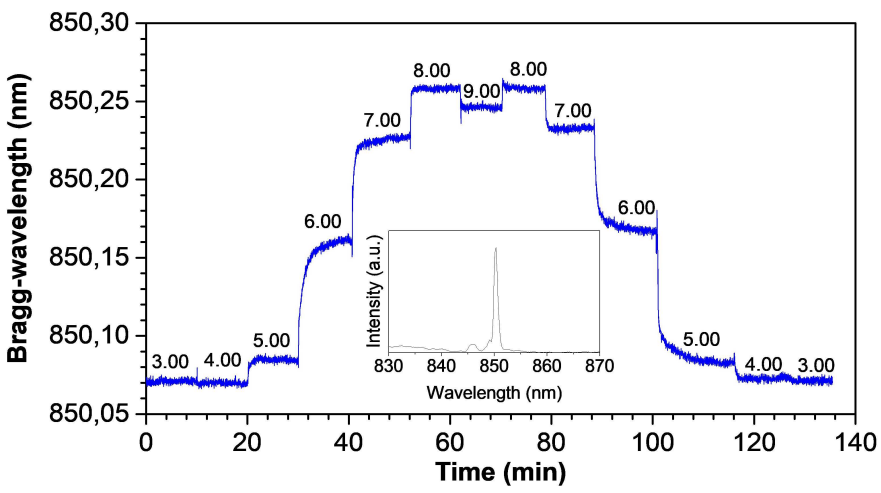

Fig. 10. Response of the $80 \mu \mathrm{m}$ etched mPOFBG pH sensor. Inset: Reflection spectrum of the sensor.

The thermal response of the etched mPOFBG $\mathrm{pH}$ sensor was investigated. A test tube filled with $\mathrm{pH} 7$ buffer solution was placed in a thermal bath on a hot plate and the temperature was increased from room temperature to $50{ }^{\circ} \mathrm{C}$ and back to room temperature in steps of $5^{\circ} \mathrm{C}$ to $10^{\circ} \mathrm{C}$ and $\lambda_{B}$ was sampled at each point as shown in Fig. 11. It is seen, that the sensor has a thermal sensitivity of $31.2 \mathrm{pm} /{ }^{\circ} \mathrm{C} \pm 0.4$ $\mathrm{pm} /{ }^{\circ} \mathrm{C}$ which is very similar to the thermal sensitivities of etched PMMA mPOFBGs without hydrogel coating, -31.5 $\mathrm{pm} /{ }^{\circ} \mathrm{C} \pm 0.4 \mathrm{pm} /{ }^{\circ} \mathrm{C}$. This means, that the presence of the thin hydrogel coating on the fiber does not significantly affect the thermal response of the FBG. This has the advantage that, for temperature cross-sensitivity compensation in real sensor applications, another FBG with different $\lambda_{B}$ can simply be placed close to the one for $\mathrm{pH}$ measurement.

\section{CONCLUSION}

We conclude that the studied all-polymer FBG $\mathrm{pH}$ sensor out-performs similar state-of-the-art $\mathrm{pH}$ sensors regarding 


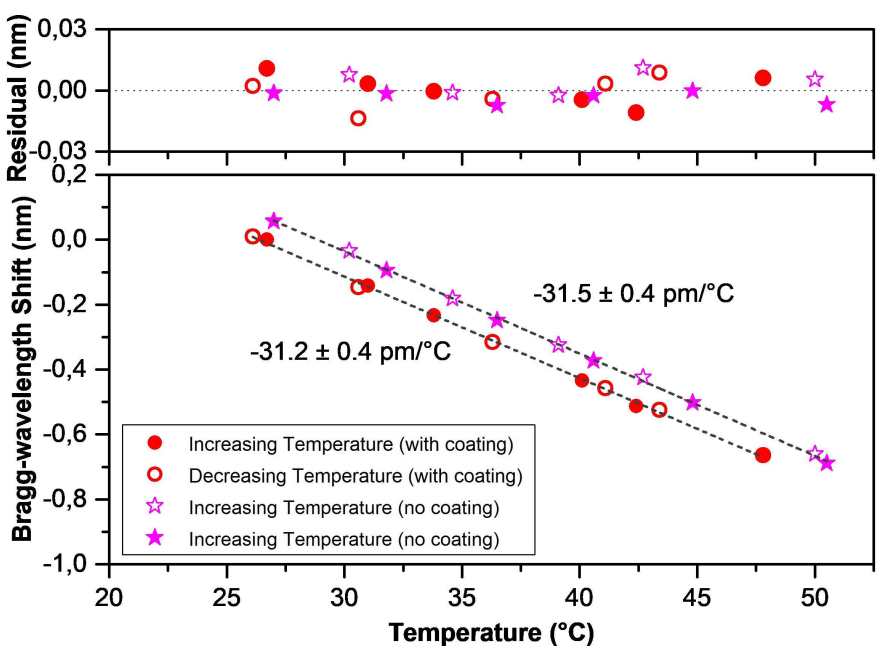

Fig. 11. Thermal response of the etched ( $\varnothing 80 \mu \mathrm{m})$ hydrogel-coated mPOFBG $\mathrm{pH}$ sensor at constant $\mathrm{pH} 7$ compared with an etched (Ø56 $\mu \mathrm{m})$ uncoated mPOFBG. Top: Residuals from the linear fit.

combined small size, robustness, sensitivity and response time. Furthermore, the hydrogel coating on the fiber does not significantly affect the thermal response of the FBG, which makes temperature cross-sensitivity compensation easy. These findings together with inherent POF properties like, no risk of breakage and ease of chemical modification (etching, roughening etc.) for integration of sensing chemicals, makes this $\mathrm{pH}$ sensor interesting for more applications than similar glass fiber FBG and hydrogel based $\mathrm{pH}$ sensors.

\section{ACKNOWLEDGMENT}

This work was supported by: The Danish Innovation Foundation as part of the innovation consortium BIOFORS (contract no. 1382-00058B); The European Maritime and Fisheries Fund; The Danish Fisheries Agency and The People Programme (Marie Curie Actions) of the European Union's Seventh Framework Programme FP7/2007-2013/ under REA Grant Agreement 608382.

\section{REFERENCES}

[1] J. I. Peterson, S. R. Goldstein, R. V. Fitzgerald, and D. K. Buckhold, "Fiber Optic pH Probe for Physiological Use," Analytical Chemistry, vol. 52, no. 6, pp. 864-869, 1980.

[2] F. Baldini, S. Bracci, and F. Cosi, "An extended-range fibre-optic $\mathrm{pH}$ sensor," Sensors and Actuators A: Physical, vol. 38, pp. 37-38, 1993.

[3] C. Egami, K. Takeda, M. Isai, and M. Ogita, "Evanescent-wave spectroscopic fiber optic pH sensor," Optics Communications, vol. 122, pp. 122-126, 1996.

[4] Z. Shakhsher, W. R. Seitz, and K. D. Legg, "Single Fiber-Optic $\mathrm{pH}$ Sensor Based on Changes in Reflection Accompanying Polymer Swelling," Analytical Chemistry, vol. 66, no. 10, pp. 1731-1735, 1994.

[5] C. R. Zamarreño, M. Hernáez, I. Del Villar, I. R. Matías, and F. J. Arregui, "Optical fiber $\mathrm{pH}$ sensor based on lossy-mode resonances by means of thin polymeric coatings," Sensors and Actuators, B: Chemical, vol. 155 , no. 1 , pp. 290-297, 2011.

[6] A. Patel and K. Mequanint, "Hydrogel biomaterials," in Biomedical Engineering, R. Fazel-Rezai, Ed. Rijeka: IntechOpen, 2011, ch. 14. [Online]. Available: https://doi.org/10.5772/24856

[7] J. Rička and T. Tanaka, "Swelling of Ionic Gels: Quantitative Performance of the Donnan Theory," Macromolecules, vol. 17, no. 12, pp. 2916-2921, 1984
[8] R. A. Siegel and B. A. Firestone, "pH-Dependent Equilibrium Swelling Properties of Hydrophobic Polyelectrolyte Copolymer Gels," Macromolecules, vol. 21, no. 11, pp. 3254-3259, 1988.

[9] T. Tanaka, "Collapse of Gels and the Critical Endpoint," Physical Review Letters, vol. 40, no. 12, pp. 820-823, 1978.

[10] T. Tanaka, I. Nishio, S.-T. Sun, and S. Ueno-Nishio, "Collapse of Gels in an Electric Field," Science, vol. 218, no. 4571, pp. 467-469, 1982.

[11] A. Richter, G. Paschew, S. Klatt, J. Lienig, K.-F. Arndt, and H.-J. P. Adler, "Review on Hydrogel-based $\mathrm{pH}$ Sensors and Microsensors," Sensors, vol. 8, no. 1, pp. 561-581, 2008. [Online]. Available: http://www.mdpi.com/1424-8220/8/1/561/

[12] T. Miyata, N. Asami, and T. Uragani, "A reversibly antigen-responsive hydrogel," Nature, vol. 399, no. 6738, pp. 766-768, 1999.

[13] Y. Murakami and M. Maeda, "DNA-responsive hydrogels that can shrink or swell," Biomacromolecules, vol. 6, no. 6, pp. 2927-2929, 2005.

[14] M. Gao, K. Gawel, and B. Stokke, "Swelling Dynamics of a DNA-Polymer Hybrid Hydrogel Prepared Using Polyethylene Glycol as a Porogen," Gels, vol. 1, no. 2, pp. 219-234, 2015. [Online]. Available: http://www.mdpi.com/2310-2861/1/2/219

[15] E. P. Jonášová and B. T. Stokke, "Bioresponsive DNA-co-polymer hydrogels for fabrication of sensors," Current Opinion in Colloid and Interface Science, vol. 26, pp. 1-8, 2016. [Online]. Available: http://dx.doi.org/10.1016/j.cocis.2016.07.001

[16] R. Kashyap, Fiber Bragg Gratings, 2nd ed. Elsevier Inc., 2010.

[17] A. Stefani, W. Yuan, C. Markos, and O. Bang, "Narrow bandwidth 850$\mathrm{nm}$ fiber bragg gratings in few-mode polymer optical fibers," I E E E Photonics Technology Letters, vol. 23, no. 10, pp. 660-662, 2011.

[18] A. Stefani, S. Andresen, W. Yuan, N. Herholdt-Rasmussen, and O. Bang, "High sensitivity polymer optical fiber-bragg-grating-based accelerometer," I E E E Photonics Technology Letters, vol. 24, no. 9, pp. 763-765, 2012.

[19] X. Liu, X. Zhang, J. Cong, J. Xu, and K. Chen, "Demonstration of etched cladding fiber Bragg grating-based sensors with hydrogel coating," Sensors and Actuators, B: Chemical, vol. 96, no. 1-2, pp. 468472,2003

[20] J. Cong, X. Zhang, K. Chen, and J. Xu, "Fiber optic Bragg grating sensor based on hydrogels for measuring salinity," Sensors and Actuators, B: Chemical, vol. 87, no. 3, pp. 487-490, 2002.

[21] I. Yulianti, A. Sahmah, M. Supa, and S. M. Idrus, "Characterization of Fiber Bragg Grating Sensor for pH Measurement," 2014 IEEE/ASME International Conference on Advanced Intelligent Mechatronics (AIM), pp. 1163-1166, 2014.

[22] X. Cheng, J. Bonefacino, B. O. Guan, and H. Y. Tam, "All-polymer fiber-optic $\mathrm{pH}$ sensor," Optics Express, vol. 26, no. 11, p. 14610, 2018. [Online]. Available: https://www.osapublishing.org/abstract.cfm?URI=oe-26-11-14610

[23] M. D. Nielsen and N. A. Mortensen, "Photonic crystal fiber design based on the V-parameter," OPTICS EXPRESS, vol. 11, no. 21, pp. 2762-2768, 2003. [Online]. Available: http://arxiv.org/abs/physics/0310065

[24] S. W. Yuan, A. Stefani, M. Bache, T. Jacobsen, B. Rose, N. HerholdtRasmussen, F. K. Nielsen, S. Andersen, O. B. Sørensen, K. S. Hansen, and O. Bang, "Improved thermal and strain performance of annealed polymer optical fiber bragg gratings," Optics Communications, vol. 284, no. 1, pp. 176-182, 2011.

[25] G. Woyessa, K. Nielsen, A. Stefani, C. Markos, and O. Bang, "Temperature insensitive hysteresis free highly sensitive polymer optical fiber bragg grating humidity sensor," Optics Express, vol. 24, no. 2, pp. 12061213, 2016.

[26] A. Stefani, K. Nielsen, H. K. Rasmussen, and O. Bang, "Cleaving of topas and pmma microstructured polymer optical fibers: Core-shift and statistical quality optimization," Optics Communications, vol. 285, no. 7, pp. 1825-1833, 2012.

[27] H. Dobb, D. Webb, K. Kalli, A. Argyros, M. Large, and M. van Eijkelenborg, "Continuous wave ultraviolet light-induced fiber bragg gratings in few- and single-mode microstructured polymer optical fibers," Optics Letters, vol. 30, no. 24, pp. 3296-3298, 2005.

[28] I.-L. Bundalo, K. Nielsen, C. Markos, and O. Bang, "Bragg grating writing in PMMA microstructured polymer optical fibers in less than 7 minutes," Optics Express, vol. 22, no. 5, p. 5270, 2014. [Online]. Available: https://www.osapublishing.org/oe/abstract.cfm?uri=oe-22-55270

[29] D. Ganziy, O. Jespersen, G. Woyessa, B. Rose, and O. Bang, "Dynamic gate algorithm for multimode fiber Bragg grating sensor systems," Applied Optics, vol. 54, no. 18, p. 5657, 2015. [Online]. Available: https://www.osapublishing.org/abstract.cfm?URI=ao-54-18-5657 
[30] H. Franke, "Optical recording of refractive-index patterns in doped poly(methyl methacrylate) films," APPLIED OPTICS, vol. 23, no. 16, pp. 2729-2733, 1984.

[31] Y. Luo, Q. Zhang, H. Liu, and G.-D. Peng, "Gratings fabrication in benzildimethylketal doped photosensitive polymer optical fibers using $355 \mathrm{~nm}$ nanosecond pulsed laser." Optics letters, vol. 35, no. 5, pp. 751-3, 2010. [Online]. Available: http://www.ncbi.nlm.nih.gov/pubmed/20195341

[32] A. K. Yetisen, H. Butt, F. da Cruz Vasconcellos, Y. Montelongo, C. A. B. Davidson, J. Blyth, L. Chan, J. B. Carmody, S. Vignolini, U. Steiner, J. J. Baumberg, T. D. Wilkinson, and C. R. Lowe, "Light-directed writing of chemically tunable narrow-band holographic sensors," Advanced Optical Materials, vol. 2, no. 3, pp. 250-254, 2014. 